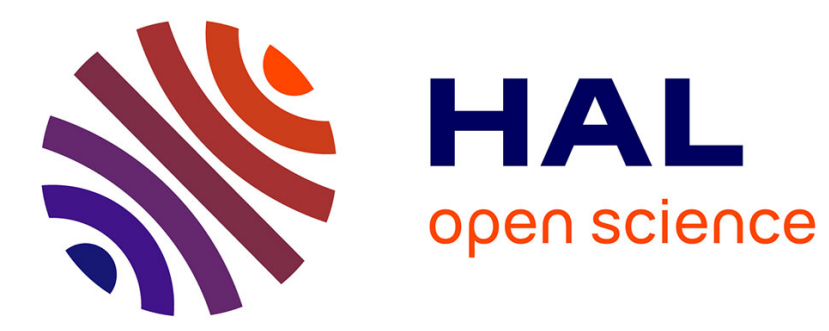

\title{
Influences and Benefits of Role Models on Social Media
} Lyndsey Jenkins, Ruoyun Lin, Debora Jeske

\section{To cite this version:}

Lyndsey Jenkins, Ruoyun Lin, Debora Jeske. Influences and Benefits of Role Models on Social Media. 15th Conference on e-Business, e-Services and e-Society (I3E), Sep 2016, Swansea, United Kingdom. pp.673-684, 10.1007/978-3-319-45234-0_60 . hal-01702198

\section{HAL Id: hal-01702198 \\ https://hal.inria.fr/hal-01702198}

Submitted on 6 Feb 2018

HAL is a multi-disciplinary open access archive for the deposit and dissemination of scientific research documents, whether they are published or not. The documents may come from teaching and research institutions in France or abroad, or from public or private research centers.
L'archive ouverte pluridisciplinaire HAL, est destinée au dépôt et à la diffusion de documents scientifiques de niveau recherche, publiés ou non, émanant des établissements d'enseignement et de recherche français ou étrangers, des laboratoires publics ou privés. 


\title{
Influences and benefits of role models on social media
}

\author{
Lyndsey Jenkins $^{\mathrm{a}}$, Ruoyun Lin ${ }^{\mathrm{b}}$, Debora Jeske ${ }^{\mathrm{a}}$ \\ ${ }^{a}$ Edinburgh Napier University, Edinburgh, United Kingdom \\ ${ }^{\mathrm{b}}$ Leibniz-Institut für Wissensmedien, Tübingen, Germany \\ l.jenkins@napier.ac.uk; r.lin@iwm-tuebingen.de; \\ d.jeske@napier.ac.uk
}

\begin{abstract}
The current paper examined three research questions. First, what are the perceived benefits for social network users who have role models online? Second, to what extent does having role models online influence one's selfpresentation on social media? And finally, are users who expect more in return (greater reciprocity) more likely to have role models on social media? Using two opportunity survey samples and exploratory analyses, study $1(N=236)$ demonstrated that having role models was associated with greater perceived support for one's career aspirations, and perceived access to information. The results of study $2(N=192)$ revealed that participants who had role models online reported that their online profile presented a more realistic self-presentation of values and priorities, as well as having higher reciprocity expectation.
\end{abstract}

Keywords. Key words: role model, social media, information-seeking, reciprocity expectations

\section{Introduction}

When we need information, support and guidance, we often seek help from those who are more qualified or experienced to assist us. These individuals may often include individuals that can be considered role models [1]. Role models are individuals that people look up to. In addition, role models may be individuals that you would hope to be like (now or in the future). This includes individuals who may be known to a person but who have not met yet [2]. Frequently, role models include people in authority or positions of respect. This often includes public officials and well known professionals (e.g., people serving in emergency services such as fire brigade, police and similar as well as educators, athletes parents, celebrities or religious leaders [3,4]). Role models are usually senior in experience and influence than other contacts $[5,6]$. The specific status, gender, experiences and rank of contacts may likewise play a role as to whether or not these contacts are considered positive role models [3,5].

Social media makes it easier for individuals to identify role models and get in touch with one another. Indeed, past evidence suggests that contacts on digital platforms play an important role in building social support and social capital [7] as these social media sites enable users to share information, create personal content and collaborate with 
other users on these sites [8]. Having a role model online may help us gain more informational benefits as they may post useful and relevant information about career paths and options publicly [2].

The 'virtual presence' of online role models may increase the effort that social network users make to connect with the role model and how they interact as well as present themselves 'in front' of others via their online profiles [2]. This may start by users paying careful attention to how they present themselves, as the role model may be aware of their interactions online [5]. At present, many of these findings about the benefits of role models on social media have not been substantiated. The purpose of the present work is to provide support for some of the hypothesized benefits whilst also paying attention to the role of reciprocity expectations.

In the following section, we outline three research questions and review the literature in an attempt to answer each. First, what are perceived benefits for social network users who have role models online? Second, to what extent does having role models online influence one's self-presentation? And third, to what extent do the expectations of social network users play a role? That is, are those who have higher reciprocity expectations more inclined to have role models because of their expectation that they would benefit from this association in the future.

\subsection{Perceived Benefits for Social Network Users}

Online contacts may form another source of support to those present in every-day life, as they can provide social support and mentoring opportunities (which have been explored as predictors of subjective career success, [9]). Past work [10] has demonstrated that people seek information by making connections through active seeking of sources, active scanning of the environment for information, and making connections through non-directed monitoring as well as connections by proxy (via other people's connections and searchers). Social networks offer information seekers several options in one place. This may play an important role in terms of young adults' readiness for career decision-making. This can be defined as the degree to which individuals feel capable to make career choices that take into account a personal circumstances and wider context variables, including social, economic and organizational variables [11]. Social networks may therefore be particularly beneficial to and shape career decision making due to their 24-hour availability and their potential to support information seeking.

Social network activities may similarly help mentees to obtain instrumental as well as emotional support $[12,13]$. Previous research has emphasized the need to consider the role of multiple sources of information and advice in career decision making $[14,15,16]$. Especially among younger adults, being able to access more information and learn from positive role models may aid career decision-making when transitioning from school or university into the workplace. The contact and interaction during information seeking may increase the willingness and readiness of students to participate in various optional career-related opportunities. Contacting role models may also represent a career strategy of its own and complement parental support - as long as the role model's achievement appears to be obtainable by the less experienced individual [17]. 
We suggest that having role models online will increase social network users' access to information and career-related planning.

\subsection{Self-presentation}

Social comparison theory [18] suggests that people evaluate their own views and achievements in relation to other people's accomplishments to gain a good understanding of themselves. Through this comparison, usually with similar others or those they aspire to be like, individuals gain insight that allows them to personally define who they are in contrast to others. This process benefits from learning about others - a process facilitated by exposure to information about others. For example, after reading role model's career experience in their posts, the user might identify what it takes to achieve certain career stages successfully but also understand requirements to develop [4]. In turn, the information could help the individuals understand how to present themselves successfully online. The verifiability of information may furthermore increase their efforts to be present a realistic - or slightly flattering - profile online and reduce their tendency to share inaccurate information about themselves (e.g., idealized).

The contact and possible exchange with role models and external advisors via social networks may further help younger adults become more knowledgeable about themselves and their career options [19]. This may be particularly important when individuals want to learn about their own future career options from others. Yet, self-presentation plays an important role as well. Social networks not only allow users to learn from their role models via their posts, but may increase awareness of managing their interactions and profiles online. This is further reinforced by the fact that many network users are increasingly aware of the fact that even their personal profiles may be viewed by others outside of role model status, including employers and the general public [20]. As a result, social desirability may shape the degree to which social network users present a realistic versus a more social desirable image that may be more polished and slightly less representative of themselves. This links with idealistic versus realistic impression management online [21,22].

\subsection{Reciprocity Expectations}

The Social Exchange Theory [23] suggests that social behavior is driven largely by the expectations of the individuals [24]. This means the interaction between individuals involves all partners negotiating and reflecting on the rewards and costs of their interpersonal relationship. The exchanges involved in relationships help build "feelings of personal obligation, gratitude and trust" (Blau, 1964, p. 94 - [25]). As a result, social network users have to balance several social expectations at the same time. This includes reciprocity expectations [26] as these may further shape online activity [27].

For example, social media users may expect that connections will be willing to reciprocate later. In other words, some users may intentionally connect with a role model with the hope that this connection will result in mutual benefits. Users who have greater reciprocity expectations may see role models as potentially useful connections than 
those who do not expect a return for favors. So users with higher reciprocity expectations might expect each other to endorse each other (LinkedIn, for example, allows users to submit small supportive statements about contacts that can be seen by other users). The 'followers' of a role model may be more willing to "like" and share the comments of their role models, reinforcing their popularity and status as a role model. In addition, network users may purposefully contact role models as they hope that mutual support and information exchange will lead to mutual long-term benefits. This raises the question of mutual expectations when social network users connect with one another (e.g., the expectation that favors will be returned) - the other side of benefits to having role models on one's network.

\section{Study 1 - Benefits}

\section{$2.1 \quad$ Method}

The focus of the first study was to examine, in the context of career-related information seeking, whether or not young adults experience potential benefits of having role models on social media when engaged in such information-seeking. The focus was to examine whether perceived career support and perceived access to information was improved amongst those social network users with role models on their social networks.

\subsubsection{Participants and Procedure}

Using an opportunity sample, we recruited 281 psychology students from three educational institutions in the American Midwest $(n=151,53.7 \%)$ and North East England $(n=130,46.5 \%)$ as part of a larger data collection effort. Data screening did not show any significant differences between the two datasets. For the purpose of the present research, we excluded all participants that did not use social media, who omitted questions on role model access, or completed only some of the questionnaire. This result in a final sample of 236 participants between the ages of 17 to 35 and on average about 20 years old $(M=20.53, S D=2.61)$. Three out of four participants were women $(77.1 \%, \mathrm{n}=182)$. Male participants made up less than a quarter of the sample $(22.9 \%$, $n=54)$.

Participants were invited via announcement in class or via email. Once participants had completed the consent form, they were asked to complete measures related to career-related decision making and information access, their social network connections (including role models) and demographics. This was followed by the debrief statement.

\subsubsection{Measures}

Study 1 included the following measures to capture career-related information seeking and engagement of young adults generally.

Occupational engagement. This was measured using nine items from the Occupational Engagement Scale-Student, OES-S [28]. An example item is: "I volunteer in an 
area that I find interesting." Responses were made on a five point scale ranging from (1) unlike me to (5) like me $(\alpha=.81, M=3.31, S D=0.66)$.

Career pursuit support. Four items were used to measure support from family and friends in pursuing career goals [29]. This subscale measures perceived emotional and instrumental support from family and friends in pursuing career goals. An example item is "I receive the encouragement I need from others to meet my career goals." Responses were made on a five point Likert type scale ranging from (1) strongly disagree to (5) strongly agree $(\alpha=.85, M=3.49, S D=0.89)$.

Likely access to information (informational support). In order to assess the extent to which individuals seek information from the online environment, the six-item Environment Exploration subscale was selected [30]. These were modified by including references to information sought from contacts on social media sites. The instructions presented to our participants stated that "How likely is it that you would ask your contacts/friends on your social media sites to get the following information?" These items did not imply that these contacts or friends had to be role models to capture general access to information from the social network. An example item is: "Information about potential career possibilities". Two items were added from the "External Search Instrumentality" subscale [30]. These items were (1) "Initiating conversations with friends and relatives about careers" and (2) "Initiating conversations with several other students about their career interviews." The response options ranged from (1) hardly ever to (5) almost always. A composite was created based on all eight items $(\alpha=.94, M=2.48$, $S D=0.80)$.

Access to role models online. In order to determine respondents' accessibility to role models online, they were asked "Have you used social media (e.g., social network sites such as Facebook, LinkedIn) to connect with potential role models?" Respondents answered either Yes $=1$, or No $=2$. Just a third of the participants $(n=85)$ reported that they had used social media to connect with a role model online, while two thirds had no such role models $(n=151)$.

Demographics. These included age and gender.

\subsection{Results}

Data screening showed unremarkable skew and kurtosis for all measures. Table 1 shows the correlations for the different measures.

In order to analyze differences in career-related and information behaviors amongst social network users with or without online role models, we used analysis of covariance. Each analysis involved age and gender as covariates as older and female network users may potentially also have more online connections but fewer role models [2]. No significant difference was observed in relation to occupational engagement $(F(1,228)$ $\left.=2.893, p=.090, \eta_{\mathrm{p}}{ }^{2}=.013\right)$. Having a role model online did not influence occupational engagement for these participants $(M=3.41, S D=0.68, n=84)$, compared to those who did not have such role models online $(M=3.23, S D=0.61, n=148)$. However, having role models online did influence the level of perceived support for career pursuit $\left(F(1,228)=6.553, p=.011, \eta_{\mathrm{p}}^{2}=.028\right)$. Those with a role model reported higher perceived career support $(M=3.69, S D=0.72, n=84)$ compared to those who did not have such role models $(M=3.42, S D=0.84, n=148)$. 
Table 1. Correlations between measures and age

\begin{tabular}{lllll}
\hline & \multicolumn{1}{c}{$(1)$} & \multicolumn{1}{c}{$(2)$} & $(3)$ & $(4)$ \\
\hline (1) Occupational engagement & 1 & & & \\
(2) Career support & $.198^{* *}$ & 1 & & \\
(3) Information access & $.260^{* *}$ & $.401^{* *}$ & 1 & \\
(4) Age & $.153^{*}$ & -.053 & .047 & 1 \\
\hline Note. $^{*} p<.05,{ }^{* *} p<.01$ & & & &
\end{tabular}

A significant influence was observed in relation to the perceived access to information $\left(F(1,228)=15.517, p<.001, \eta_{\mathrm{p}}{ }^{2}=.064\right)$. As anticipated, having a role model online significantly increased perceived access to information for those who had role models online $(M=2.76, S D=0.71, n=84)$ compared to those who $\operatorname{did} \operatorname{not}(M=2.35$, $S D=0.78, n=148)$. This difference also remained when taking into account occupational engagement as a covariate $(p<.05)$, which suggests that individual engagement in career-related information seeking has a significant role in accessing information, although the benefits of having access to role models appear to be particularly prominent.

\section{Study 2 -Self-presentation and Reciprocity Expectations}

\subsection{Method}

The second study enabled us to explore whether having role models on social media influences online self-presentation, and the relationship with reciprocity expectation.

\subsubsection{Participants and Procedure}

Data collection involved two different samples $(N=217)$, including a UK student sample $(\mathrm{n}=129)$ and a Facebook opportunity sample $(n=63)$. Preliminary data screening revealed no significant differences between the two samples. However, we only retained cases that provided full information about social media use, role models and the key constructs of interest. The final sample included 192 participants, including 43 males and 147 females (plus 2 missing values). Participants' age ranged from 16 to 69 $(M=24.01, S D=9.20)$.

Participants were invited via a university research portal, email and short messages on social media. Once participants had completed the consent form, they were asked to complete measures related to reciprocity expectations, social media use (including role models), presentation on social media and demographics. This was followed by the debrief statement.

\subsubsection{Measures}

Realistic self-presentation on social networks. We asked several questions. First, we asked about their own evaluation of how realistically the participants presented 
themselves online on their most used website. This question asked: "Overall, to what extent does your social networking profile that is visible to your network reflect your personality, priorities and values? Think about the site that you use the most (if you use more than one social media platform)" $(M=6.52, S D=1.88)$. Second, we created slight variants of the same question by only changing the start of each question to ask about specific contacts. Therefore, we created a question for family: "To what extent your family members would agree that your social activities on this site reflect ...?" $(M=$ $6.12, S D=1.99)$. And third, "To what extent would your close friends agree that your social activities on this site reflect ...?" $(M=6.76, S D=1.92)$. The final question asked: "To what extent your colleagues would perceive your social activities on this site reflect $\ldots$ ?" $(M=5.83, S D=2.08)$. The response options for all questions were: (0) not at all to (10) to a great extent.

Reciprocity expectations. This was measured using 10 items from the 27 -item Reciprocity questionnaire by [25]. The scale was shortened to include only items that would be potentially transferable to the online context. An example item is: "If someone does a favor for me, I am ready to return it." Responses were made on a five point scale ranging from (1) very untrue to (7) very true $(\alpha=.63, M=2.70, S D=0.60)$.

Access to role models online. All participants were asked "Do you have any contacts on your social networking sites that are role models for you?" More than half $(n=115)$ had contacts that were role models, with just over a third had no such role models $(n=$ 77).

Demographics. This included gender and age.

\subsection{Results}

Data screening showed unremarkable skew and kurtosis for reciprocity and the presentation measures. Table 2 shows the correlations for the different measures.

In order to analyze differences in career-related and information behaviors amongst social network users with or without online role models, we used analysis of covariance. Each analysis involved age and gender as covariates. Efforts of realistic selfpresentation (match between online profile and user's personality, priorities and values), as judged by the participants themselves, similarly differed amongst participants with and without role models $\left(F(1,185)=7.963, p=.005, \eta_{\mathrm{p}}^{2}=.041\right)$.

Table 2. Correlations between measures and age

\begin{tabular}{llccccr}
\hline & $(1)$ & $(2)$ & $(3)$ & $(4)$ & $(5)$ & $(6)$ \\
\hline (1) Reciprocity & 1 & & & & & \\
(2) Present. online: Self & .058 & 1 & & & & \\
(3) Present. online: Family & .016 & $.711^{* *}$ & 1 & & & \\
(4) Present. online: Friends & -.005 & $.774^{* *}$ & $.753^{* *}$ & 1 & & \\
(5) Present. online: Colleagues & -.029 & $.462^{* *}$ & $.622^{* *}$ & $.578^{* *}$ & 1 & \\
(6) Age & $-.251^{* *}$ & -.028 & .020 & -.028 & .070 & 1 \\
\hline
\end{tabular}

Note. ${ }^{*} p<.05,{ }^{* *} p<.01$

Participants with role models actually reported higher scores - more realistic selfpresentation online $(M=6.84, S D=1.76, n=113)$, than those without models $(M=$ 
$6.05, S D=1.97, n=76)$. A similar result was obtained when we asked participants how true their family would rate their online presentation $\left(F(1,185)=7.800, p=.006, \eta_{\mathrm{p}}^{2}\right.$ $=.040)$. Again, ratings were higher amongst participant with role models $(M=6.44$, $S D=1.95, n=113)$ than those without $(M=5.64, S D=1.95, n=76)$. However, no significant difference was noted when participants were asked about the perceptions of close friends $(\mathrm{F}(1,185)=1.863, p=.174, \eta \mathrm{p} 2=.010)$ and colleagues $(\mathrm{F}(1,185)=.960$, $\left.p=.329, \eta_{\mathrm{p}}^{2}=.005\right)$.

With regard to reciprocity expectations, a significant difference was observed $(\mathrm{F}(1$, $\left.182)=10.277, p=.002, \eta_{\mathrm{p}}^{2}=.053\right)$. Having a role model online was associated with greater expectations of reciprocity amongst these participants $(M=4.61, S D=0.58, n$ $=111)$, compared to those who did not have such role models online $(M=4.51, S D=$ $0.58, n=75)$.

\section{Discussion}

The presence of social media in everyday life, both at a personal and professional level, has provided new opportunities for individuals to connect to mentors and role models online. The current paper examined three research questions. First, what are the perceived benefits for social network users who have role models online? Second, to what extent does having role models online influence one's self-presentation on social media? And finally, are users who expect more in return (greater reciprocity) more likely to have role models on social media? In order to provide first answers to these exploratory questions, we used the results from two different studies, the participants of which were part of two opportunity samples.

The benefits associated with role models were explored in the first study. The results of group comparison showed that having role models was associated with greater perceived support for one's career aspirations and perceived access to information. These results suggest that having role models in one's networks may boost social network users' future-oriented engagement and improve information access. This is an important contribution to what has only been hypothesized previously. Further research may wish to consider the influence of online role models social network users engage with in person (as this might reinforce the influence of the role model). In our study, we cannot be sure which sources of influence had a greater impact beyond the two groups (parents or role models; see [16]) as role models may have included parental figures as well [31]). In addition, it would be interesting to replicate our research with professionals instead of students as age and experience may play an important role in terms of who is sought out as a role model. Future research may further wish to consider how participants seek out information: active seeking of sources, active scanning of the environment for information, and making connections through non-directed monitoring as well as connections by proxy [10].

A second area of interest in our work related concern was therefore how realistic social network users choose to present themselves online. This was examined in study 2 by considering the degree to which the online profile reflects the user's real personality, priorities and values. In our work, we focused on individual behavior rather than social norms as influences on strategic self-presentation (see work on social norms by 
[32]). In contrast to expectations, participants with role models reported more realistic self-presentation of values and priorities than those who did not have role models online. Results are in line with work by [33] who showed that true self-expression appeared to be positively associated with personal disclosure on Facebook walls. Moreover, those who expressed their 'true self' online tended to be more active social media users who posted content that was both personally revealing as well as emotional content that may increase the accuracy of self-presentation in front of all other contacts. The current findings further contribute to current knowledge about self-disclosure. This suggests that Goffman's [34] notion of 'performing the self' and impression management may not necessarily supported as the relationship between role models and their contacts may require a greater degree of honesty in order to maintain the trust and good will of this relationship. Similarly, impression management via social media may be impaired by the fact that it is difficult for social network users to interpret online cues when the interactions are entirely computer-mediated [35].

When the participants were asked to what extent their social networking profile visible to their network (e.g., newsfeeds, your posts, comments, shares and "likes") also reflects their personality, priorities and values, we saw a significant difference in terms of perceived fit, depending on who assessed this fit between the profile and the actual user's characteristics. A significant difference was observed when participants were asked their own perceptions of presentation fit (between profile and their actual personality, priorities and values) as well as how realistic their family would evaluate the fit of their online profile to the user's personality, priorities and values. The results suggest that individuals with role models believed that their online profile would match their personal characteristics - at least in their own eyes and close others such as their family members' perspective. This suggests that social network users want to portray their genuine self and be perceived as the 'real deal' in order to foster their relationship with role models. Researchers interested in this area may moreover review previous work on role transitions [36]. This work proposed that people strive to be authentic or true to themselves (in line with our work) in the process of exploring provisional selves.

However, our conclusions may need to be interpreted with caution. We did not collect a measure to assess social desirability efforts or impression management efforts. More polished profiles may influence the extent to which role models agreed to join on social media, especially when they know the real person and become aware of the discrepancy between their real self and their online persona. This suggests a form of backlash: Overly unrealistic self-presentation may actually reduce role model willingness to be connected - although this would have to be tested further. Some research suggests that role models may bring about change in those who admire them by helping them to reflect on values as well as identify those that are relevant and attainable [3]. This may actually reinforce more realistic self-presentation on online profiles over time - certainly an area for future research.

The results for the perceived perspectives from two other groups (friends' and colleagues') did not match those obtained for self-ratings and family. No significant differences were obtained when participants were asked to imagine their friends or colleagues rating their profile. These findings may be the result of two variables. First, 
familiarity - participants' genuine character may be less familiar to friends and colleagues than oneself and the family (who are more likely to know the real 'you'), in line with the idea of weak and strong social ties. In addition, people take different roles in different social environments. Unfortunately, we did not have enough information about the nature of the relationship between our participants and their role models (e.g., how often they interact online \& offline, whether the role model's opinion has a determinant influence on one's future career, and so on). Future research may wish to examine this further as some networking may be driven by more utilitarian motives. For example, some contacts may be less interested in individual attributes of a social media connection, but rather look towards their usefulness due to their ties and connections within a social network. This might explain why friends and colleagues may not worry about the degree to which the profile of a user matches their characteristics (e.g., personality, priorities and values) - they may not judge their network contacts based on their realistic self-presentation but by what they can do for them by association [37]).

Group comparisons in study 2 further revealed that those participants who had role models online did have higher reciprocity expectations. In other words, they expected that a good turn or doing a favor on their part would also be returned by others. That said, we acknowledge an important caveat: since the data are cross-sectional, we cannot exclude the possibility that people with higher reciprocity expectation (or occupational engagement in the first study) are more likely to add a role model on social media. In other words, reverse causality may play a role in our results as both studies make causal assumptions which need to be tested in follow-up experiments. We do not know if these reciprocity expectations are mutual as some role models may expect some (non-financial) return on investment. We do not know how actively and effectively the role models of our participants and our participants themselves communicated their expectations. Future research may wish to examine reciprocity expectations as a control variable rather than as an outcome variable.

\subsection{Conclusions}

The study explored the possibility that having a role model on social media may help individuals on social media to gain more career information (study 1 ). These results suggest that having role models in one's network may boost social network users' future-oriented engagement and improve information access. At the same time, the presence of role models may make social network users more cautious, resulting in more accurate self-presentation online (study 2). However, participants who had role models online also a higher reciprocity expectation (study 2), which suggests that they expect favors to be repaid in the future. This suggests that the benefits of having role models may align with expectations of future returns.

\section{$5 \quad$ References}

1. Kuperminc, G., Emshoff, J.G., Reiner, M.N., Secrest, L.A., Niolon, P.H., Foster, J.D.: Integration of mentoring with other programs and services. In: D.L. DuBois, 
M.J. Karcher (eds.), Handbook of Youth Mentoring, pp. 314-339. Thousand Oaks, CA, Sage (2005)

2. [8el, U., Bowser, G.: Real stories about real women: Communicating role models for female tourism students. J. Teach. Travel Tour., 13, 170-183. doi: 10.1080/15313220.2013.786466 (2013)

3. Brace-Govan, J.: More diversity than celebrity: A typology of role model interaction. J. Soc. Mark., 3(2), 111-126. doi: 10.1108/JSOCM-05-2012-0079 (2013)

4. Buksa, I., Mitsis, A.: Generation Y's athlete role model perceptions on PWOM behavior. Young Consum., 12(4), 337-347. doi: 10.1108/17473611111185887 (2011)

5. Boissin, J.-P., Branchet, B., Delanöe, S., Velo, V.: Gender's perspective of role model influence on entrepreneurial behavioral beliefs. Int. J. Bus., 16(2), 182-206 (2011)

6. Collins, J., Cooke, D.O.: Creative role models, personality and performance. J. Manag. Dev., 32(4), 336-350. doi: http://dx.doi.org/10.1108/02621711311326347 (2013)

7. Vitak, J., Ellison, N.B., Steinfield, C. The ties that bond: Re-examining the relationship between Facebook use and bonding social capital. In: Proceedings of the $44^{\text {th }}$ Hawaii International Conference on System Sciences, 1-10. doi: 10.1109/HICSS.2011.435 (2011)

8. Elefant, C.: The "Power" of social media: Legal issues and best practices for utilities engaging social media. Energy Law J., 32(1), 1-56 (2011)

9. Ng, T.W.H., Feldman, D.C.: Subjective career success: A meta-analytic review. J. Vocat. Behav., 85, 169-179. doi: 10.1016/j.jvb.2014.06.001 (2014)

10. McKenzie, P.J.: A model of information practices in accounts of everyday-life information seeking. J. Doc., 59(1), 19-40. doi: 10.1108/00220410310457993 (2003)

11. Sampson, J.P., Jr., Peterson, G.W., Reardon, R.C., Lenz, J.G.: Using readiness assessment to improve career services: A cognitive information processing approach. Career Dev. Quart., 49, 146-174. (2000)

12. Higgins, M.C. (Changing careers: The effects of social context. J. Organ. Behav., 22, 595-618. doi: 10.1002/job.104 (2001).

13. Higgins, M.C., Kram, K.E.: Reconceptualizing mentoring at work: A developmental network perspective. Acad. Manage. Rev., 26, 264-288. doi: 10.5465/AMR.2001.4378023 (2001)

14. Creed, P.A., Hughes, T.: Career development strategies as moderators between career compromise and career outcomes in emerging adults. J. Career Dev., 40, 146163. doi: 10.1177/0894845312437207 (2013)

15. Metheny, J., Hawley McWhirter, E.: Contributions of social status and family support to college students' career decision self-efficacy and outcome expectations. J. Career Asses., 21, 378-394. doi: 10.1177/1069072712475164 (2013)

16. Slaten, C.D., Baskin, T.W.: Examining the impact of peer and family belongingness non career decision-making difficulties of young adults: A path analytic approach. J. Career Assess., 22, 59-74. doi: 10.1177/1069072713487857 (2014)

17. Lockwood, P., Kunda, Z.: Increasing the salience of one's best selves can undermine inspiration by outstanding role models. J. Pers. Social Psychol., 76(2), 214-228 (1999).

18. Festinger, L.: A theory of social comparison processes. Hum. Relat., 7(2) 117-140. doi: 10.1177/001872675400700202 (1954) 
19. Sampson, J.P., McClain, M.-C., Musch, E., Reardon, R.C.: Variables affecting readiness to benefit from career interventions. Career Dev. Quart., 61, 98-109. doi: 10.1002/j.2161-0045.2013.00040.x (2013)

20. Joos, J.G.: Social media: New Frontiers in hiring and recruiting. Employment Relations Today, Spring, 51-59. doi: 10.1002/ert.20188 (2008)

21. Gosling, S.D., Augustine, A.A., Vazire, S., Holtzman, N., Gaddis, S.: Manifestations of personality in online social networks: Self-reported Facebook-related behaviors and observable profile information. Cyber Psych. Behav., Soc. Network., 14, 483488. doi: 10.1089/cyber.2010.0087 (2011).

22. Sievers,K., Wodzicki, K., Aberle, I., Keckeisen, M., Cress, U.: Self-presentation in professional networks: More than just window dressing. Comp. Hum. Behav., 50, 25-30. doi:10.1016/j.chb.2015.03.046 (2015)

23. Homans, G.C.: Social behavior as exchange. Am. J. Sociol., 63(6), 597-606. doi: http://www.jstor.org/stable/2772990 (1958)

24. Reber, A.S.: Dictionary of Psychology ( $2^{\text {nd }}$ ed). Penguin Reference (1995)

25. Perugini, M., Gallucci, M., Presaghi, F., Ercolani, A.P.: The personal norm of reciprocity. Eur. J. Pers, 17, 251-283. doi:10.1002/per.474 (2003)

26. Blau, P.M.: Exchange and Power in Social Life. New York: Wiley (1964)

27. Lampinen, A., Lehtinen, V., Cheshire, C., Suhonen, E.: Indebtedness and reciprocity in local online exchange. In: Proceedings of CSCW, 23-27 Feb., San Antonio, Texas, USA, 1-11. doi: 10.1145/2441776.2441850 (2013)

28. Cox, D.W., Krieshok, T.S., Bjornsen, A.L., Zumbo, B.D.: Occupational Engagement Scale-Student: Development and initial validation. J. Career. Assess. published online 12 February 2014. doi: 10.1177/1069072714523090 (2014)

29. Rottinghaus, P.J., Buelow, K.L., Matyja, A., Schneider, M.R.: The Career Futures Inventory - Revised: Measuring dimensions of career adaptability. J. Career Assess., 20, 123-139. doi: 10.1177/1069072711420849 (2012).

30. Stumpf, S.A., Colarelli, S.M., Hartman, K.: Development of the Career Exploration Survey. J. Vocat. Behav., 22, 191-226. doi:10.1016/0001-8791(83)90028-3 (1983)

31. Direnzo, M.S., Weer, C.H., Linnehan, F.: Protégé career aspirations: The influence of formal e-mentor networks and family-based role models. J. Vocat. Behav., 83, 41-50. doi: 10.1016/j.jvb.2013.02.007 (2013)

32. Uski, S., Lampinen, A.: Social norms and self-presentation on social network sites: Profile work in action. N. Media Soc., 18(3), 447-464. doi: 10.1177/1461444814543164 (2016).

33. Seidman, G.: Expressing the "true self" on Facebook. Comp. Hum. Behav., 31, $367-$ 372. doi: 10.1016/j.chb.2013.10.052 (2014)

34. Goffman, E.: The Presentation of Self in Everyday Life. New York: Doubleday and Anchor Books (1959).

35. Lin, R., Jeske, D.: Impression management via content-dependent "liking" on social media. Int. J. Web Based Communities (in press).

36. Ibarra, H.: Provisional selves: experimenting with image and identity in professional adaptation. Admin. Science Quart., 44, 764-791. doi: 10.2307/2667055 (1999)

37. Kadushin, C.: Understanding social networks: Theories, concepts, and findings. New York, Oxford University Press (2012) 